MIDAS

Museus e estudos interdisciplinares

$7 \mid 2016$

Varia

\title{
Expositor interativo para a comunicação de amostras geológicas do MM Gerdau - Museu das Minas e do Metal
}

Interactive displayer for exploring geological samples in the MM GerdauMuseu das Minas e do Metal

Roberto Vaz, Rui Raposo e Mário Vairinhos

\section{OpenEdition}

\section{Journals}

Edição electrónica

URL: http://journals.openedition.org/midas/1086

DOI: $10.4000 /$ midas. 1086

ISSN: 2182-9543

Editora:

Alice Semedo, Paulo Simões Rodrigues, Pedro Casaleiro, Raquel Henriques da Silva, Ana Carvalho

\section{Refêrencia eletrónica}

Roberto Vaz, Rui Raposo e Mário Vairinhos, « Expositor interativo para a comunicação de amostras geológicas do MM Gerdau - Museu das Minas e do Metal », MIDAS [Online], 7| 2016, posto online no dia 29 novembro 2016, consultado no dia 01 maio 2019. URL : http://journals.openedition.org/ midas/1086; DOI : 10.4000/midas.1086

Este documento foi criado de forma automática no dia 1 Maio 2019

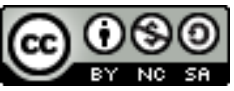

Midas is licensed under a Creative Commons Attribution-NonCommercial-ShareAlike 3.0 International License 


\section{Expositor interativo para a comunicação de amostras geológicas do MM Gerdau - Museu das Minas e do Metal}

Interactive displayer for exploring geological samples in the MM GerdauMuseu das Minas e do Metal

Roberto Vaz, Rui Raposo e Mário Vairinhos

\section{NOTA DO EDITOR}

Artigo recebido a 27.03.2015

Aprovado para publicação a 10.01.2016

Agradecimentos

Em especial: Ana Veiga, Helena Mourão, Márcia Guimarães, Soraia Vasconcelos, Daniela Matos, Leonardo Miranda, Alaôr de Morais, Gledson de Assis, Alexandre Bezerra, Educativo do MM Gerdau - Museu das Minas e do Metal e Biblioteca Pública Estadual Luiz de Bessa.

\section{Introdução}

1 A noção de museu enquanto «instituição permanente sem fins lucrativos, ao serviço da sociedade e do seu desenvolvimento, aberta ao público, que adquire, conserva, investiga, comunica e expõe o património material e imaterial da humanidade e do seu meio envolvente com fins de educação, estudo e deleite» (ICOM 2007) não se manteve constante ao longo do tempo. Partindo desta definição, adotada e difundida pelo Conselho Internacional de Museus (ICOM) compreende-se que o pressuposto dos museus é o de proporcionar à sociedade o acesso à educação, oferecendo momentos de estudo ou de 
lazer, de forma a cooperar para o seu desenvolvimento, comprometendo-se a adquirir, a salvaguardar e dar a conhecer o património material e imaterial da humanidade e do meio que a envolve (Desvallées e Mairesse 2010).

2 Ainda que de modo bastante discreto, é possível constatar a preocupação por parte de algumas instituições culturais em atender às necessidades e aos anseios dos seus públicos, nomeadamente através da inclusão de tecnologias inovadoras para comunicar as coleções e incentivar a visita a estes espaços, proporcionando novas experiências de interação e de contacto com as exposições (Chelini 2012). Em alguns casos, estes recursos tecnológicos são apontados como indispensáveis por facilitarem a reprodução de histórias e de processos intangíveis; noutros, por contribuírem para o aprofundamento de informações acerca do que não pode ser exposto, conferindo acesso a réplicas e a reconstruções digitais (Chanda 2013). Adicionalmente, permitem oferecer detalhes complementares de forma mais atrativa e acessível para os visitantes, sem sobrecarregar o ambiente com excesso de informação. Para tal, interessa que a sua utilização se revele como um meio e não como um fim, onde, idealmente, o acervo material deve ser combinado com os conteúdos digitais, proporcionando uma experiência útil e que facilite a comunicação conveniente dos diversos assuntos (Israel 2011).

3 Entre os meios tecnológicos adotados para o incremento da experiência da visita a museus, apontam-se sucintamente o recurso a quiosques interativos e superfícies multitoque (Kidd, Ntalla e Lyons 2011), a disponibilização de guias móveis, mais recentemente em smartphones e tablets (Neves 2013), a utilização de projeções interativas e o recurso à realidade aumentada (Rowe 2013), a descoberta de informações via fiduciais de códigos QR - Quick Response Code - e etiquetas de NFC - Near Field Communication dispostas nos espaços museológicos (Pereira 2013), e ainda a possibilidade de visitar museus fora dos edifícios físicos, recorrendo-se a ilustrações e a representações destes online - museus virtuais (Geser e Niccolucci 2012). Repare-se que estas soluções tecnológicas oferecem muitas vezes experiências multissensoriais no contexto da visita aos museus, sobretudo a nível visual e auditivo, acessíveis a grande parte da população. Todavia, se se atentar à realidade da deficiência visual, constata-se que, apesar de inovadoras e altamente sofisticadas, estas soluções não facultam nem o acesso, nem a compreensão efetiva das exposições, tornando-se irrelevantes para estes públicos. De acordo com Classen (2007), na esmagadora maioria dos casos, os artefactos podem apenas ser olhados, contrastando com a carência de utilização de um dos principais sentidos humanos que permite a interação com o mundo: o tato. A possibilidade de se poder estabelecer contacto físico com as peças expostas apresenta a vantagem de complementar sensorialmente aspetos que a visão, por si só, não consegue apreender, tais como o peso, a textura, os materiais e a rigidez dos artefactos (Classen 2007; Morgan 2012).

4 Nesta sequência, o trabalho desenvolvido em contexto de dissertação de mestrado (Vaz 2014) insere-se na área da informação e da comunicação com novos media digitais, mais especificamente em interfaces tangíveis - que se caracterizam pela manipulação de conteúdos digitais a partir de objetos físicos - para a comunicação de acervo museológico, disponibilizado para manuseio e utilizados como base para a interação com o sistema.

5 Ao longo do artigo são abordados os processos de conceção e avaliação de um protótipo de uma interface tangível desenvolvida no MM Gerdau - Museu das Minas e do Metal, que integra o Circuito Cultural Praça da Liberdade, localizado na região central de Belo Horizonte, Brasil, que permitiu a 23 visitantes (entre os quais, três invisuais) a interação física com quatro amostras geológicas pertencentes ao acervo. Para tal, foi seguida uma 
metodologia de design participativo (participatory design), durante a qual se contou com a colaboração de profissionais do museu das áreas das geociências, da educação, da tecnologia, da museografia e da comunicação, centrando-se a sua realização na metodologia de design de interação, com o intuito de proporcionar uma utilização agradável por parte dos visitantes do MM Gerdau. Pretendeu-se também que o módulo interativo pudesse ser utilizado de modo independente por segmentos do público com insuficiência a nível visual.

\section{Enquadramento teórico e presença de interfaces tangíveis em museus}

6 Tomando em consideração a definição de museu estabelecida pelo ICOM, anteriormente apresentada, poder-se-á inferir que os museus, abertos ao público, assumem desde a sua génese a função de servir a sociedade com o intuito de contribuir para a sua educação. Constata-se, no entanto, que a realidade de um público poder espontaneamente usufruir do espaço e das coleções dos museus como forma de contribuição pessoal é uma conquista da trajetória dos museus ao longo de séculos de história, não sendo admissível há cerca de 260 anos atrás (Suano 1986; Veiga 2013). Desde então, o discurso museográfico tem-se modificado e evoluído no sentido de encontrar espaço para reformular o conceito clássico de comunicar o património, mais recentemente, ao adotar tecnologias inovadoras, que oferecem cenários mais modernos de interação dos visitantes com as exposições e a renovação da experiência da visita (Chanda 2013; Hernández 2009).

7 A necessidade de envolver os museus com novos paradigmas de inovação que possibilitem a proliferação de mensagens com as quais os diferentes públicos se identifiquem e se sintam atraídos é apontada por Hernández (2009), consumando estas instituições como empenhadas em adaptar-se e ajustar-se às demandas e expetativas dos visitantes. Por conseguinte, e de forma a ganhar relevo junto das sociedades contemporâneas, observase que a interação nos museus começa a ganhar expressão, na medida em que os públicos, os profissionais de museus e outras pessoas estabelecem uma relação mais próxima com a própria instituição (Chanda 2013).

8 A interação com sistemas digitais sofreu igualmente um percurso evolutivo: aquando do aparecimento do computador, o utilizador encontrava-se limitado ao uso de um rato e de um teclado como meio de interagir com o ambiente apresentado no ecrã, de forma sequencial no tempo - deste modo, apenas se conseguia realizar uma ação de cada vez. Em 1995, George Fitzmaurice, Hiroshi Ishii e William Buxton propuseram o termo Graspable User Interface, que motivou uma quebra neste paradigma: através de blocos palpáveis - bricks - foi possível manipular objetos digitais, tornando possível, entre outras ações, controlar a posição das representações virtuais, fazendo uso simultâneo de ambas as mãos. As entradas no sistema deixaram de ser sequenciais, assistindo-se uma multiplexagem do espaço, permitindo a manipulação de diversos aspetos virtuais ao mesmo tempo, o que na prática resultou no aumento das funcionalidades suportadas pelo sistema, reduzindo-se a complexidade (Fitzmaurice, Ishii e Buxton 1995). Passados dois anos, Hiroshi Ishii e Brygg Ullmer propuseram o modelo conceptual das TUI - Tangible User Interfaces - onde combinaram a arquitetura de sistema da computação ubíqua com o modelo conceptual da realidade aumentada e com a computação física, de forma a converter o mundo numa interface (Ishii e Ullmer 1997). Assim, os objetos tangíveis 
passaram a permitir simultaneamente representar e manipular conteúdos digitais, abrindo espaço para a inclusão deste conceito em diversos aspetos do quotidiano, nos quais se têm demonstrado efectivos. Apontam-se algumas das suas implicações: no domínio do ensino e da aprendizagem, em novos cenários de visualização de informação, na projeção e na resolução de problemas mais intuitivamente, através da interação táctil, no entretenimento e nos jogos, na música e na performance (Shaer e Hornecker 2009), na adaptabilidade de artefactos em ambiente doméstico (Vairinhos 2014) e na visita a espaços museológicos, foco da problemática do presente artigo.

Os estudos de caráter científico da utilização de interfaces tangíveis para a comunicação e a interação em museus são ainda escassos, quando comparados com outros domínios de aplicação destas soluções. Não obstante, identificam-se alguns exemplos de aplicação prática. O National Palace Museum (Taipei, Taiwan), acolheu em 2009 a exposição Harmony and Integrity: The Yongzheng Emperor and His Times, na qual foi disponibilizada uma interface tangível - Yongzheng Emperor's Interactive Tabletop. A interação com esta interface permitiu aos visitantes conhecer as várias fases da vida do imperador, através da manipulação de seis representações físicas com diferentes indumentárias de Yongzheng, e uma outra para interagir com um calendário, onde eram apresentadas, em três cenários, imagens de artefactos pertencentes ao seu reinado (Hsieh et al. 2010).

Partindo da ideia que o contacto com a arte deve combinar os processos de ver, descobrir, estimular e emocionar fazendo uso da imaginação e da sensibilidade para experienciar e interpretar as exposições, foi inaugurado, em 2006, o Museum Lab, fruto da colaboração entre o Musée du Louvre e o Dai Nippon Printing (DNP). A apresentação Diplomacy and Sèvres Porcelain, Prestige and the French Art of Living in the 18th Century, iniciada em 2010 no Louvre-DNP Museum Lab, em Tóquio, incluiu uma área dedicada à exploração de artefactos, recorrendo a TUIs. Neste caso, os visitantes tiveram ao seu dispor um conjunto de miniaturas físicas de algumas das porcelanas em exposição, que ao serem colocadas na área específica para o efeito, faziam surgir num ecrã os objetos que representavam, em três dimensões. Assim, as peças puderam ser observadas de vários ângulos à medida que eram manuseadas, e conhecidos detalhes pouco evidentes a olho nu, através da interação com as figuras tridimensionais geradas virtualmente (Dai Nippon Printing e Musée du Louvre 2010).

11 No mesmo espaço, em 2011, na exposição Offerings for Eternity in Ancient Egypt: A Question of Survival foi disponibilizada a interface Offering Table of Horiraa que, fazendo uso da realidade mista, consistia num espelho que monitorizava os movimentos que os visitantes executavam com os objetos tangíveis, refletindo as imagens reais adicionadas de conteúdos virtuais. Um dos elementos manuseáveis era um turíbulo, que aparecia projetado na interface como se estivesse efetivamente a queimar incenso e ao inclinar um vaso sobre a mesa, era apresentada informação virtual que representava água corrente. Ao tocar no artefacto real da mesa de oferta de Horiraa surgia no espelho uma animação sobre a reflexão desta superfície (Hara e Oda 2012; Louvre-DNP Museum Lab 2011).

A exposição El Niño Azul, Goya and Spanish Painting in the Louvre, em 2012, incluiu um espaço dedicado ao entendimento de fatores ligados à pintura: a instalação The Painting, a Material object possibilitou aos visitantes manipular oito elementos físicos, entre os quais, quatro representavam materiais próprios para pintar, cujo manuseamento permitia atuar nas diferentes camadas que compõem a obra, com o intuito de dar a conhecer as várias fases da sua criação. Outros quatro objetos despoletavam imagens com as alterações 
provocadas no trabalho original pelo tempo, e por fatores externos, como a humidade, $\mathrm{o}$ calor e a exposição à luz (Louvre-DNP Museum Lab 2012).

Na apresentação A Masterpiece of Ancient Greece: a World of Men, Gods and Heroes, em 2013, os visitantes puderam fazer uso de uma TUI na área «Heracles, a Myth in Images», onde manuseavam uma cópia da estatueta Heracles Resting para interagir com imagens de artefactos da Grécia antiga, projetadas num mapa interativo, que respondia à posição do objeto tangível (Louvre-DNP Museum Lab 2013).

14 No Musée d'Histoire Naturelle (Lille, França), os visitantes podem descobrir a coleção de minerais manipulando discos tangíveis numa superfície, que representam átomos. Cada um destes tem associado a si exemplares de rochas constituídas por esta partícula, sendo possível a combinação entre os vários elementos. Para além dessas peças, o sistema Tangible Lille é composto por um ecrã disposto na vertical, onde são apresentadas imagens e informações relativas às rochas - como a dureza, a composição, a fórmula química e a aplicação - e por uma superfície horizontal plana, onde as peças são movidas, para associar e quebrar a combinação entre os átomos, e giradas, para selecionar os minerais que se pretendem conhecer em detalhe (Dalbavie 2014).

15 A título de conclusão da enumeração de exemplos de interfaces tangíveis em museus, assinala-se o trabalho ArtVis, desenvolvido para a exploração de obras de arte europeias que compõem o museu virtual Web Gallery of Art. Trata-se de uma palete com controlos físicos que permite explorar um mapa digital e navegar por uma linha do tempo, onde as obras se encontram ordenadas. Adicionalmente, foi incorporada tecnologia em diferentes objetos de arte físicos, que pretendem representar pinturas, esculturas, entre outros, que, quando colocados em contacto com a palete, permitem explorar detalhes sobre o autor, entre os quais a escola a que pertence, o movimento estético e os trabalhos que serviram de inspiração para a realização da sua obra (Dumas et al. 2014).

Em sintonia com os trabalhos apresentados, no projecto em análise no presente artigo, pretendeu-se que exemplares geológicos pudessem ser manuseados pelos visitantes, e, de acordo com a interação, que o sistema fosse fornecendo informações relativas aos mesmos. Através deste contacto físico com os objetos pode abrir-se espaço para uma nova experiência de visita e de perceção da exposição, que mediada tecnologicamente, poderá permitir que se complemente sensorialmente os conteúdos em discussão, facultando, além do mais, o acesso à exposição por parte de visitantes com insuficiência visual.

\section{Metodologias: conceção, implementação e avaliação do protótipo funcional}

17 O desenvolvimento e avaliação do protótipo do expositor interativo foi implementado no MM Gerdau - Museu das Minas e do Metal. Inaugurado em março de 2010, o Museu foi concebido para destacar a relação da história e das expressões culturais do Estado de Minas Gerais com a riqueza das suas minas e recursos naturais, revelando duas das suas principais atividades económicas - a mineração e a metalurgia - e o seu papel junto da sociedade contemporânea.

18 Os temas desenvolvidos nas exposições do Museu são explorados recorrendo à tecnologia e à interatividade de uma forma lúdica, ao longo de 18 salas e 44 interfaces digitais, sendo que apenas três exemplares do acervo estão disponíveis para contacto direto pelos visitantes. Com o objetivo de aumentar a interação com as peças geológicas e o seu 
conhecimento mais aprofundado durante a visita ao Museu, foram disponibilizadas quatro amostras pertencentes à coleção: madeira fossilizada, água-marinha, muscovita e sílex.

19 Durante o processo de conceção do protótipo, foi seguida uma metodologia de design participativo (Spinuzzi 2002) em colaboração com profissionais do MM Gerdau - Museu das Minas e do Metal de diversas áreas de atuação. O projeto contou ainda com participantes exteriores à instituição, que auxiliaram na criação do projeto de mobiliário para o expositor e na gravação dos conteúdos sonoros a apresentar aquando da interação com a interface. Por sua vez, toda a implementação do projeto foi centrada nos estudo de design de interação, tendo decorrido sessões de trabalho com colaboradores do museu e com elementos a quem o projeto se dirigia especificamente - possíveis visitantes - com o intuito de tentar proporcionar uma experiência de utilização agradável por parte dos públicos.

20 Para a avaliação do protótipo, junto de uma amostra de utilizadores constituída por 23 participantes - três invisuais e 20 visualmente aptos - foi autorizado pelo MM Gerdau Museu das Minas e do Metal a inclusão da interface no espaço museológico. Assinala-se que os visitantes cegos foram contactados previamente e aceitaram deslocar-se ao Museu, enquanto os restantes se encontravam espontaneamente no espaço museológico. Desta forma, a metodologia adotada para a avaliação foi a field trial ou avaliação in situ, a qual pressupõe que no final da interação sejam aplicados elementos de recolha de dados, junto dos participantes no estudo. A presente secção reparte-se nas fases de conceção e implementação do protótipo funcional, abordando-se em seguida as sessões de avaliação da interface.

\section{Conceção e implementação do expositor interativo}

21 Tomámos como elementos de apoio para o estudo de design de interação a definição apontada por Goodman, Stolterman e Wakkary (2011) - disciplina que tem como propósito especificar o conjunto de condutas digitais que sucedem como resposta aos estímulos provenientes quer de aparelhos diversos, quer resultantes da ação humana. 0 modelo de interação a implementar teve ainda em conta o intuito primário referido por Norman (2002) - o de desenvolver produtos interativos utilizáveis, isto é, capazes de proporcionar experiências de utilização ricas e agradáveis, e, ao mesmo tempo, simples e efetivos no modo de os utilizar. Paralelamente, foi dada especial atenção a alguns dos princípios de usabilidade estudados, de forma a obter um bom modelo conceptual e, consequentemente, uma boa experiência de interação (Norman 2002; Preece, Rogers e Sharp 2002).

Para a comunicação das quatro amostras geológicas pretendeu-se que, de acordo com o manuseamento das mesmas, fossem apresentadas informações a nível gráfico e sonoro. A principal finalidade de inclusão desta última foi a de proporcionar a pessoas com deficiência visual o contacto com as mesmas informações disponibilizadas graficamente aos visitantes visualmente capacitados. Neste contexto, as locuções, gravadas em português, incluíram descrições detalhadas de aspetos palpáveis das amostras (tais como clivagem, sistema cristalino e detalhes da textura), quer para proporcionar uma exploração mais imersiva, quer para garantir a fácil diferenciação entre elas. Quanto às informações de caráter científico das peças do acervo, exploraram-se os processos de formação, as composições químicas e as suas principais características; as curiosidades 
históricas, a sua utilização e as maiores ocorrências no Brasil foram também temáticas em destaque.

Quanto à interação com o sistema, definiu-se que o ato de levantar uma amostra seria interpretado como a demonstração de interesse em saber mais sobre a mesma, enquanto o movimento de pousar apontaria para o termo da intenção de conhecer tais pormenores. A adoção desta linguagem de interação visou conseguir uma boa visibilidade e uma sensação de mapeamento instintivo, em que cada uma das ações fosse associada ao desencadeamento de uma operação específica.

Ao longo da construção do protótipo verificou-se a necessidade de delimitar claramente a área correspondente a cada uma das amostras - denominadas de constraints - com o fim de proporcionar aos visitantes o reconhecimento inequívoco dos locais onde a interação com a interface conduz a resultados. Para tal, foi projetada uma película limitadora, disposta sobre a superfície do expositor, na qual quatro regiões assumem dimensões e formas congéneres aos recortes apresentados pelas quatro amostras geológicas. Adicionalmente, pretendeu-se fornecer algum tipo de retroação indicadora do sucesso das ações efetuadas aquando da manipulação dos elementos tangíveis do sistema, com o intuito de facilitar a devolução dos mesmos aos locais correspondentes. Dado que as amostras do MM Gerdau - Museu das Minas e do Metal apresentavam cores distintas, concluiu-se que o fornecimento de feedback a nível visual poderia ser vantajoso neste caso, para mostrar os efeitos imediatos das ações realizadas: cada vez que uma peça fosse levantada, a luminosidade na área assumia uma cor semelhante à desta, enquanto se todas elas estivessem dispostas na interface, a luz era branca - somatório de todas as cores.

Para além da interação individual com cada uma das quatro peças do acervo, foi concebida a possibilidade de permitir aos visitantes perceberem o porquê das diferenças entre duas amostras. Assim, sempre que fossem levantadas duas amostras geológicas em simultâneo, os conteúdos gráficos e sonoros seriam relativos a ambas, realizando-se uma comparação por temáticas em comum.

Do estudo acima descrito resultou o modelo de interação apresentado na figura 1.

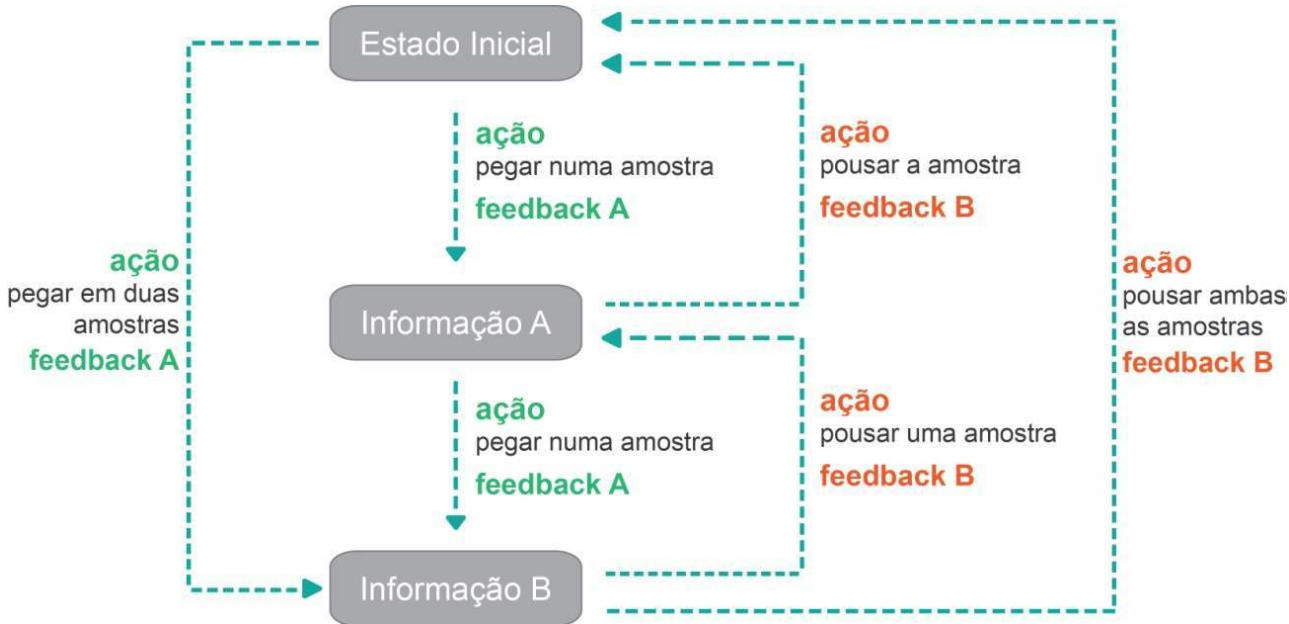

Fig. 1 - Modelo de interação do expositor interativo

Os retângulos a cinza representam informações visuais e sonoras e "feedback A" e " feedback B" indicam, respetivamente, acender ou apagar a luz sob a área da amostra. No "Estado Inicial" vê-se projetado o ecrã com as quatro amostras geológicas a informar o 
visitante que pode pegar nelas, sem nenhum som. Em "Informação A", o utilizador encontra-se a explorar tactilmente um dos minerais (fig. 2), enquanto ouve a locução correspondente e assiste aos conteúdos gráficos. Ao manusear outra amostra, é apresentada a "Informação B", gráfica e sonora, sobre características comparativas de ambas as peças do acervo (fig. 4). Ao pousar uma das amostras passa-se para o estado anterior e a iluminação da área respetiva apaga-se, ao passo que se duas amostras forem devolvidas à interface em simultâneo, é apresentado o ecrã inicial da aplicação e não se ouve nenhuma locução. Na figura 2, é possível observar a interação com um dos exemplares geológicos: a área da amostra em utilização encontra-se iluminada com cor semelhante à sua e as das restantes peças, apagadas.

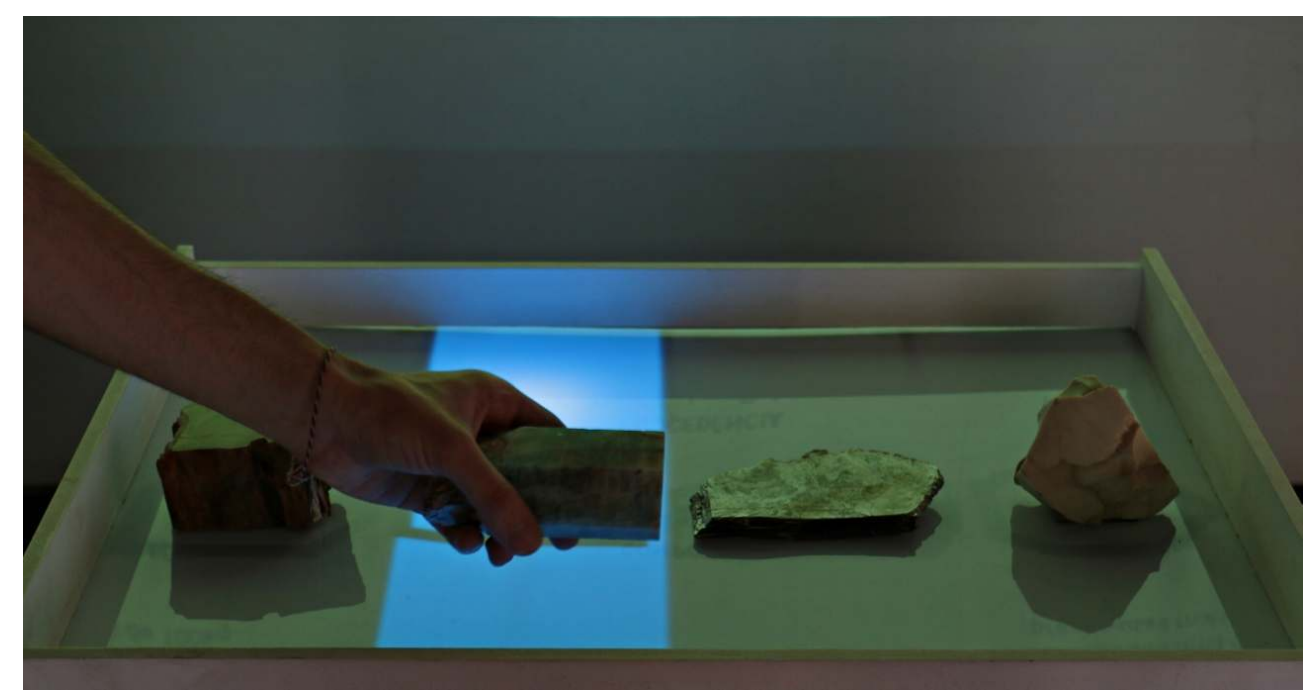

Fig. 2 - Interação com a amostra de água-marinha, 2015. Museu das Minas e do Metal Fotografia de Leonardo Miranda

Após o estudo de viabilidade técnica, definiu-se que para a concretização do modelo de interação projetado seriam utilizados quatro sensores de força, para detetar a presença ou não dos exemplares geológicos, e quatro atuadores luminosos para fornecer feedback visual aos visitantes. Para verificar o estado da interação, fez-se uso de um microcontrolador que, por sua vez, se encontrava ligado a um computador. A este último ligou-se um projetor - para a apresentação dos conteúdos visuais - e duas colunas de som - para a reprodução das locuções previamente gravadas.

Na figura 3 observa-se a instalação do expositor (no percurso da coleção principal do MM Gerdau - Museu das Minas e do Metal), com as quatro amostras geológicas dispostas no topo e os conteúdos gráficos iniciais projetados, onde a superfície se encontra iluminada com a mesma cor e são visíveis as áreas em torno das peças geológicas. 


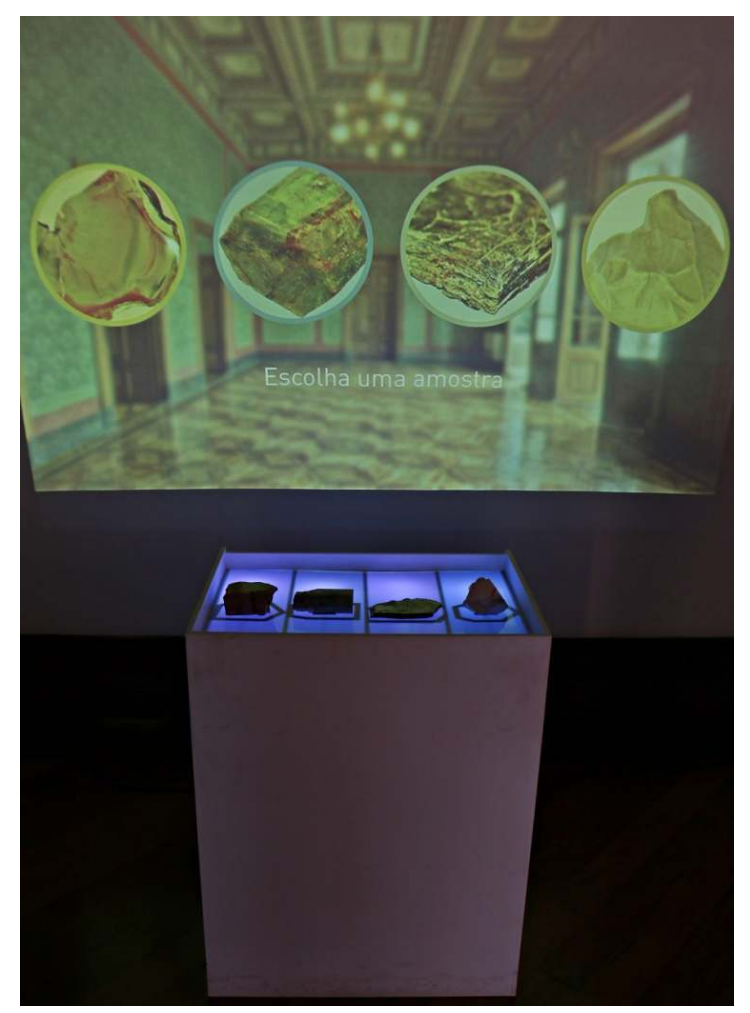

Fig. 3 - Módulo interativo implementado no museu, 2015, MM Gerdau - Museu das Minas e do Metal Fotografia de Leonardo Miranda

Ressalta-se que para a produção dos conteúdos sonoros foi organizada através de uma chamada pública, à qual compareceram 15 voluntários, entre os quais se apurou a voz que efetuou as dez gravações sonoras, quatro referentes a cada amostra geológica e seis de comparação entre elas; os textos informativos estiveram a cargo da curadora do Museu. Por sua vez, a peça de mobiliário foi projetada em parceria com uma designer de produto e concebida por um colaborador do Museu.

31 Na figura 4, um visitante com duas amostras geológicas em mãos assiste a temáticas comparativas. 


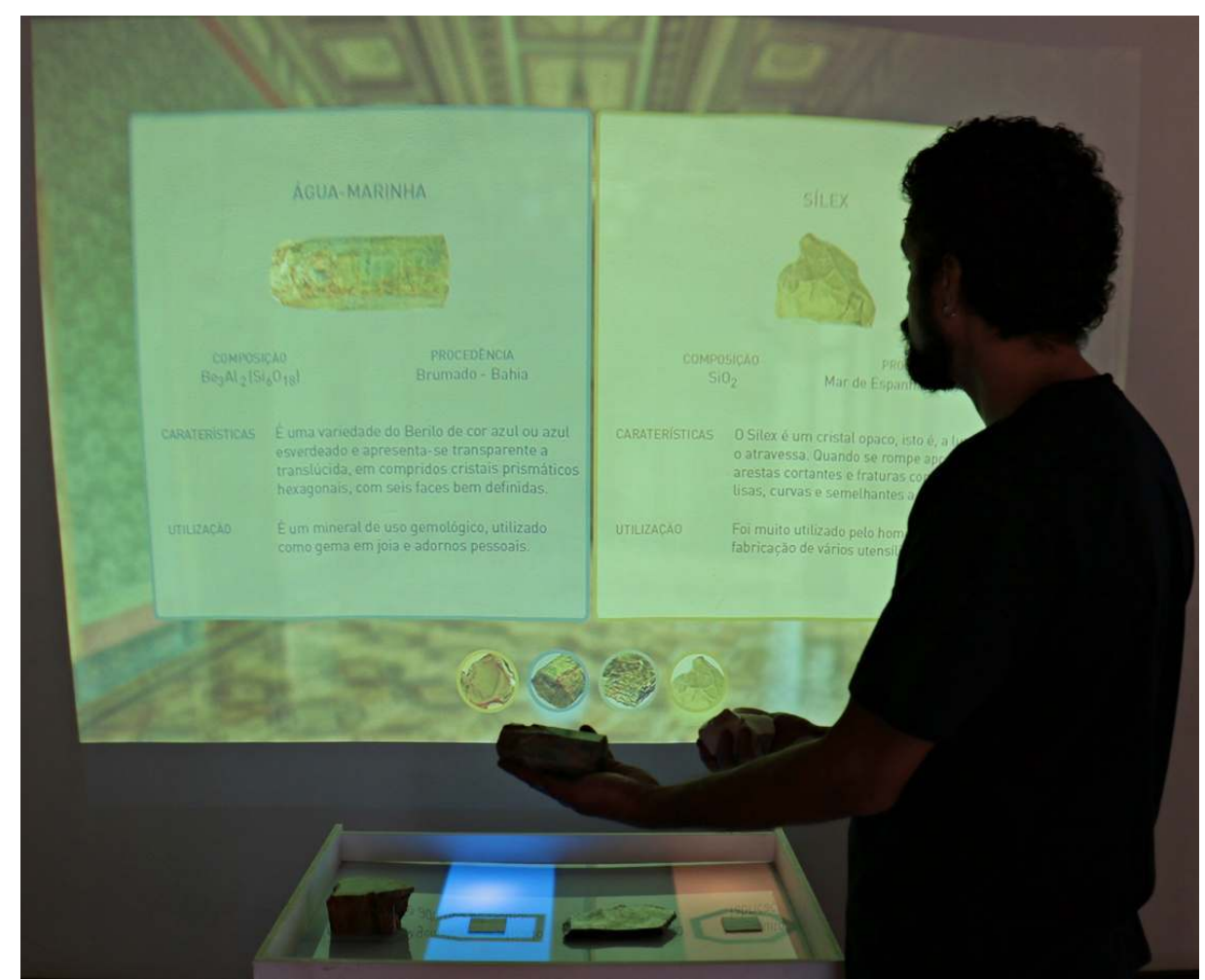

Fig. 4 - Visitante assiste a informações de dois exemplares, 2015, MM Gerdau - Museu das Minas e do Metal.

Fotografia de Leonardo Miranda

\section{Sessões de avaliação do protótipo funcional}

32 Para a avaliação da experiência de utilização do expositor interativo foi seguida a metodologia de avaliação field trial, que se caracteriza por contemplar a integração do produto desenvolvido no contexto real de utilização, apresentando as vantagens de ser mais natural e menos invasivo para os utilizadores, dado que facilita a libertação dos constrangimentos que se verificam em laboratório. Em oposição, permite um menor controlo e a dificuldade de implementação vê-se incrementada (Poulson, Ashby e Richardson 1996). De acordo com Shaer e Hornecker (2009) não existem métodos de avaliação desenvolvidos especificamente para as tangible user interfaces, sendo que a recolha de dados quantitativos, realizada através de estudos comparativos ou de avaliações heurísticas, e a observação direta da interação dos utilizadores com o sistema dados qualitativos - se apresentam como soluções possíveis para conseguir alcançar conclusões específicas.

Os principais objetivos da avaliação passaram por perceber a experiência de utilização e as considerações dos visitantes em relação aos aspetos hedónicos e pragmáticos da interação com o expositor interativo. Para tal, tentou-se compreender se o uso da interface tangível, como mediadora de comunicação de temáticas acerca das quatro amostras geológicas, foi ou não agradável; estudar os aspetos ligados à complexidade da interação necessária para assistir aos conteúdos e se os utilizadores se sentiram isolados enquanto faziam uso do sistema, ou se essa ação contribuiu para a partilha de informações no espaço museológico. Por outro lado, pretendeu-se concluir se os 
participantes consideraram o número de peças do acervo satisfatório e se as informações apresentadas, na sua forma e conteúdo, foram interessantes.

A avaliação do protótipo funcional decorreu entre os dias 27 e 28 de maio de 2014 no primeiro andar do MM Gerdau - Museu das Minas e do Metal, na área museológica definida previamente para a inclusão do expositor, tendo-se contado com a participação de 23 visitantes, representantes da amostra para o estudo. Entre o total, três apresentavam deficiência visual. A escolha do local pressupôs o cumprimento de cinco requisitos: a presença de uma câmara de segurança com ângulo de visão orientado para os elementos do acervo, uma parede de cor clara para a projeção dos conteúdos gráficos, a não interferência a nível sonoro com as outras atrações do Museu, a existência de duas tomadas elétricas e a presença de pelo menos um monitor junto da interface. De forma a organizar e a tornar mais explícito os momentos de avaliação, consideraram-se dois casos distintos: a amostra de participantes invisuais e participantes visualmente capacitados.

Para o caso dos visitantes cegos foi-lhes apresentada a interface e, após a interação, foi aplicado um inquérito por questionário. Assinala-se que o modelo de interação do expositor previa apenas a utilização individual, pelo que os participantes foram questionados sobre a ordem pela qual gostariam de usar o sistema; definida a escala de avaliações, um monitor seguiu com a visita pelo MM Gerdau - Museu das Minas e do Metal com os dois participantes que não estavam a efetuar a avaliação. No início das sessões de teste todos os objetos que os visitantes invisuais transportavam foram recolhidos, de forma a libertar as mãos para uma interação livre. Foi efetuado o reconhecimento dos limites do móvel e a profundidade da superfície, bem como foi identificada a disposição das quatro amostras geológicas e a distância a que se encontravam entre si. Findo este processo, iniciou-se a avaliação. Salienta-se que ao invés de traçar um plano de tarefas a executar, optou-se por permitir que os visitantes tomassem contacto livre com o acervo, sem limitação de tempo. Terminada a interação, foi lido em voz alta um questionário com as perguntas direcionadas para os participantes invisuais e foram registadas as respostas dadas.

Por sua vez, os 20 visitantes com habilitação visual foram convidados a interagir livremente com o protótipo, sem recorrer a nenhuma lista de tarefas, e, após a mesma, cada um deles respondeu a um inquérito por questionário. Para todos os casos foi referido que o expositor interativo permitia tomar conhecimento individual das amostras e ainda estabelecer comparação entre duas, de cada vez. À semelhança do que aconteceu na situação dos testes com os participantes invisuais, também não foi imposto limite de tempo nem traçado um plano de tarefas a executar.

\section{Avaliação do expositor interativo: apresentação e discussão de resultados}

37 A amostra do estudo caracterizou-se por $83 \%$ de visitantes do sexo feminino e $17 \%$ do sexo masculino, sendo que $53 \%$ dos indivíduos se encontravam na faixa etária compreendida entre os 15 e os 35 anos, $39 \%$ entre os 36 e os 55 anos, $4 \%$ com idade inferior a 15 anos e os restantes $4 \%$, com idade superior a 66 anos.

De forma a estudar as qualidades hedónicas e pragmáticas relacionadas com a interação estabelecida com o expositor - resultados na tabela 1 - e com o intuito de compreender a adequação dos conteúdos apresentados - resultados na tabela 2 - foi utilizada uma escala 
de medida de Likert de 5 pontos, isto é, com cinco campos de resposta. 0 número inferior (1) representa a situação menos desejável e o superior (5) a que se tentou alcançar ao longo do projeto. Para cada grupo de participantes na avaliação - visuais e invisuais assinalaram-se o número de respostas e a percentagem que representavam, em cada caso.

Tabela 1 - Resultados da medição das qualidades hedónicas e pragmáticas da interação com o expositor interativo

\begin{tabular}{|c|c|c|c|c|c|c|c|}
\hline & Participantes & 1 & 2 & 3 & 4 & 5 & \\
\hline \multirow{2}{*}{ Interação complicada } & Visuais & - & - & - & - & $\begin{array}{l}20 \\
(100 \%)\end{array}$ & \multirow{2}{*}{ Interação simples } \\
\hline & Invisuais & - & - & - & $\begin{array}{ll}1 & (33,3 \% \\
) & \end{array}$ & $\begin{array}{l}2(66,7 \% \\
)\end{array}$ & \\
\hline \multirow{2}{*}{ Interação desagradável } & Visuais & - & - & - & $\begin{array}{l}1 \\
(5 \%)\end{array}$ & $\begin{array}{l}19 \\
(95 \%)\end{array}$ & \multirow{2}{*}{ Interação agradável } \\
\hline & Invisuais & - & - & - & - & $\begin{array}{l}3 \\
(100 \%)\end{array}$ & \\
\hline \multirow[t]{2}{*}{ Interação não prática } & Visuais & - & - & $\begin{array}{l}1 \\
(5 \% \\
)\end{array}$ & - & $\begin{array}{l}19 \\
(95 \%)\end{array}$ & \multirow[t]{2}{*}{ Interação prática } \\
\hline & Invisuais & - & - & - & $\begin{array}{l}2 \\
(66,7 \%)\end{array}$ & $\begin{array}{l}1 \quad(33,3 \% \\
)\end{array}$ & \\
\hline \multirow{2}{*}{$\begin{array}{l}\text { Interação } \\
\text { desinteressante }\end{array}$} & Visuais & - & - & - & $\begin{array}{l}1 \\
(5 \%)\end{array}$ & $\begin{array}{l}19 \\
(95 \%)\end{array}$ & \multirow{2}{*}{$\begin{array}{l}\text { Interação } \\
\text { motivadora }\end{array}$} \\
\hline & Invisuais & - & - & - & - & $\begin{array}{l}3 \\
(100 \%)\end{array}$ & \\
\hline
\end{tabular}

Analisando a tabela 1 , verifica-se que a totalidade dos visitantes visualmente capacitados considerou que a interação foi simples e $66,67 \%$ dos participantes invisuais também. Contudo, um deles assinalou o campo 4 da escala de medição, pelo que se conclui que a interação não foi tão simples quanto para os outros casos. Deste último grupo, todos consideraram a interação agradável, bem como $95 \%$ dos visitantes com capacidade visual, sendo que um elemento - representante de $5 \%$ das respostas - apontou que a interação não foi tão agradável quanto para os demais. Dos 20 participantes visuais, 95\% referiram que a interação foi prática e $5 \%$ assinalaram a resposta média entre as opções antagónicas. Porém, $66,67 \%$ dos elementos invisuais não consideram a interação inteiramente prática, tendo assinalado a opção 4 da escala de Likert. No que à motivação da interação concerne, a totalidade destes últimos participantes apontaram que se sentiram motivados, bem como $95 \%$ dos visitantes visualmente habilitados, ao passo que um deles considerou a interação menos motivadora do que para a restante amostra. 
Na tabela 2 apresentam-se os dados sobre os conteúdos apresentados na forma gráfica e de áudio, dados obtidos junto dos participantes no estudo. Refere-se que as perguntas direcionadas para os visitantes visualmente aptos incluiu quer as locuções, quer as projeções, ao passo que os participantes invisuais avaliaram apenas as informações audíveis.

Tabela 2 - Dados referentes às considerações acerca dos conteúdos apresentados

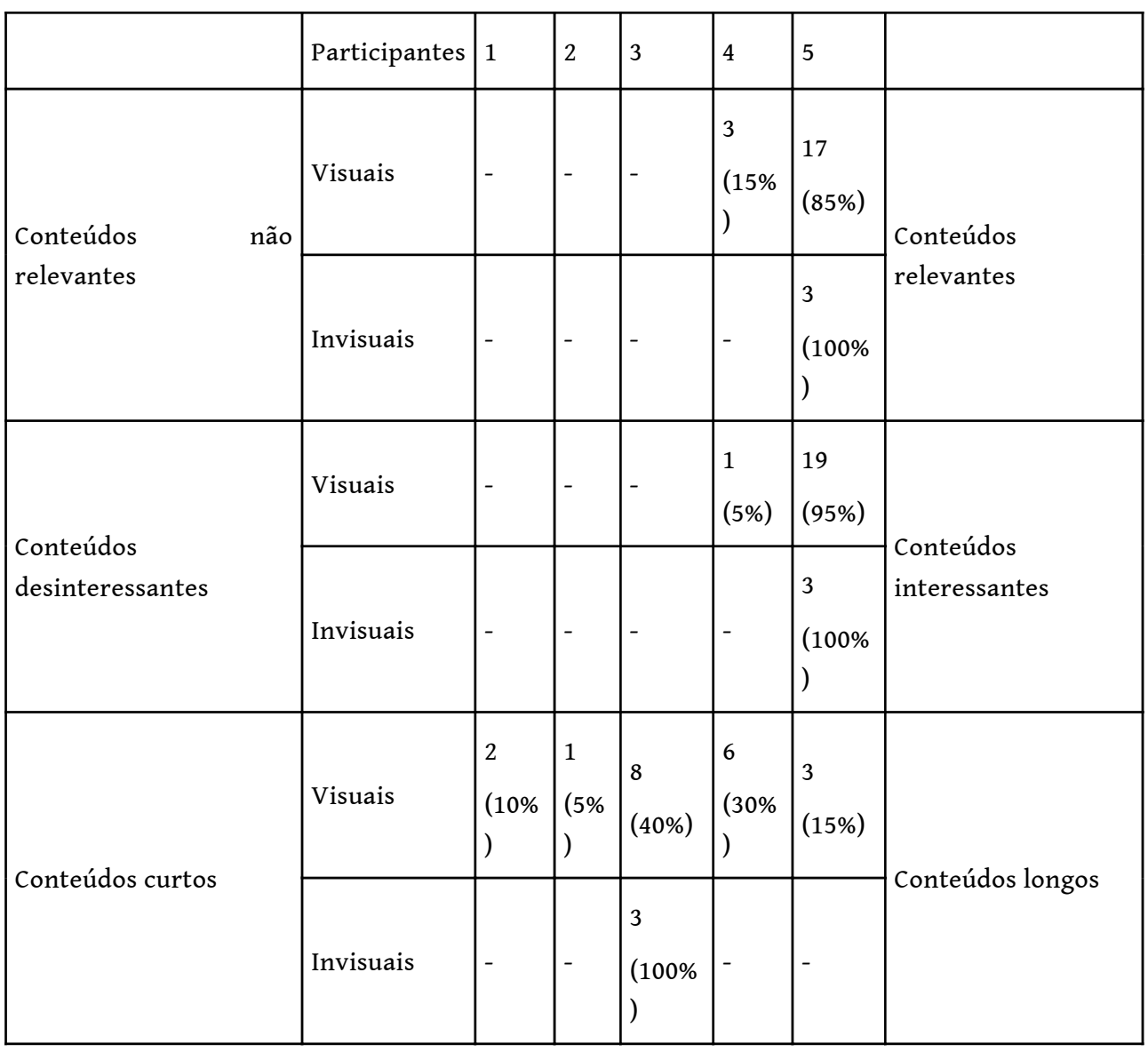

Observando a tabela 2, constata-se que $85 \%$ dos elementos do grupo visual apontaram que os conteúdos eram relevantes e $15 \%$ assinalaram o ponto 4 da escala de medição. Por sua vez, a totalidade dos visitantes invisuais consideraram as informações das locuções relevantes e interessantes. Já $95 \%$ dos participantes visuais corroboraram com o interesse dos conteúdos apresentados e um deles - representativo de $5 \%$ da amostra - assinalou um menor interesse. Quanto à duração das locuções, os três visitantes invisuais consideramnas como adequadas (nem curtos, nem longos), assim como $40 \%$ do grupo de visuais. Deste último, 30\% apontaram como duração média a longa, 15\% referiram que foi longa, $10 \%$ como curta e $5 \%$ entre média e curta.

Quando questionados se o número de amostras geológicas a disponibilizar deveria ser ou não maior que o atual (quatro exemplares do acervo do Museu), $61 \%$ da amostra total respondeu que sim e os restantes $39 \%$ que não. Aos participantes invisuais foi perguntado se as informações das locuções facilitaram na distinção entre as quatro amostras geológicas e a totalidade respondeu afirmativamente. Por fim, de forma a compreender se a interação com o expositor conduz ou não ao isolamento do visitante, $78,3 \%$ da amostra 
considerou que o sistema facilita o compartilhamento, $17,4 \%$ assinalou o ponto 4 da escala de medição e 4,3\% - um visitante - que não facilitava o compartilhar de informações, mas também não conduzia ao isolamento do visitante (ponto 3 da escala de Likert).

Após o preenchimento do questionário, os participantes foram convidados a comentar a experiência de utilização. Entre as observações verbalizadas pelos elementos da amostra de visitantes com deficiência visual transcrevem-se os seguintes: "Os outros museus deviam pegar nesta ideia como referência"; "O áudio estava muito claro e as amostras geológicas disponíveis são muito interessantes"; "Deve aumentar o número de amostras"; e "Muito diferente, novidade! Não imaginava que ia ter um jeito de pegar nas pedras e ouvir informações sobre elas. É simplesmente enriquecedor". Do total de 20 participantes visualmente aptos, 13 escreveram comentários relativos à experiência de utilização do expositor, tais como: "Sugiro que tenha uma fonte de luz de cima para baixo, para melhor visualização das amostras geológicas"; "Ter disponível um número maior de painéis expositivos com amostras diferentes"; "Por experiência em outros museus, considero a possibilidade de manusear e observar com cuidado as amostras geológicas uma forma interativa e mais prazerosa de conhecer, considerando que outros museus não apresentam esta possibilidade"; "O projeto é simplesmente fantástico, permitindo a interação completa e despertando grande prazer no toque, visualizar as cores, formatos e principalmente conhecer a riqueza das pedras e gemas. Adorei e deveria ser aplicado em todos os aspetos da nossa vida, pois o que é tátil é emoção pura!"; e "Parabéns pelo trabalho. A acessibilidade nos museus precisa ser cada vez mais intensificada".

\section{Conclusões e trabalho futuro}

Tomando em consideração as diferentes soluções tecnológicas existentes atualmente para a comunicação de exposições em museus, explorou-se ao longo do artigo a proposta de um módulo interativo como mediador da apresentação de peças da coleção do MM Gerdau - Museu das Minas e do Metal. Através deste módulo, os visitantes (na faixa etária compreendida sobretudo entre os 15 e os 35 anos, sexo feminino) puderam manusear exemplares do acervo geológico, à medida que conheciam os detalhes sobre os mesmos. Disponibilizadas nas formas auditivas, as informações mostraram-se acessíveis a visitantes com insuficiência a nível visual (e aos visualmente aptos, que puderam assistir também a conteúdos gráficos), porém, não foi alcançada a total utilização independente da interface por parte destes participantes no estudo.

Através dos resultados obtidos pela medição dos aspetos hedónicos e pragmáticos de interação com o protótipo funcional, conclui-se que a experiência de utilização foi bastante positiva, tanto para o caso dos três visitantes invisuais, quanto para os 20 participantes visualmente aptos. De um modo geral, constatou-se que os elementos do público apreciaram o contacto táctil com as amostras geológicas e assistir em simultâneo aos conteúdos informativos, e que, de certa forma, essa interação levou à partilha de informações no espaço museológico. No entanto, compreende-se a fragilidade inerente ao manuseio de acervo por motivos de possível danificação e de segurança. Sobre a coleção, a maioria dos visitantes revelou o desejo de ver aumentado o número de exemplares disponíveis para interação, e alguns sugeriram replicar a experiência noutros espaços do MM Gerdau - Museu das Minas e do Metal e noutros museus, o que leva a concluir que a primeira experiência de contacto com o protótipo foi bem recebida. Posto isto, 
compreende-se que este sistema baseado em interfaces tangíveis para a comunicação do acervo geológico e mineral tem espaço de aplicação e de exploração dentro do Museu.

Como linhas de trabalho futuras, pretende-se desenvolver investigação no sentido de facultar uma maior acessibilidade na utilização de expositores interativos deste género, pensar em novas formas de comunicar o acervo e fazer uso da tecnologia como meio de proporcionar uma conexão com os restantes objectos do MM Gerdau - Museu das Minas e do Metal, ambicionando uma experiência e uma memória de utilização que perdurem para além do momento da visita.

\section{BIBLIOGRAFIA}

Chanda, Supreo. 2013. “The Special Visitor: Each and Every One of Us.” ICOFOM Study Series (42): 83-96.

Chelini, Maria. 2012. “Novas Tecnologias para... Novas (?) Expografias.” Revista Museologia \& Interdisciplinaridade 1 (2): 59-71.

Classen, Constance. 2007. "Museum Manners: The Sensory Life of the Early Museum." Journal of Social History 40 (4): 895-914.

Dai Nippon Printing, e Musée du Louvre. 2010. "Diplomacy and Sèvres Porcelain, Prestige and the French Art of Living in the 18 th Century. Louvre - DNP Museum Lab." [Press release], Tokyo. http://www.museumlab.eu/press/pdf/Louvre-DNPMuseumLab_7_PressRelease_EN.pdf

Dalbavie, Juliette. 2014. “La Table Interactive du Musée d'Histoire Naturelle de Lille” La Lettre de l'OCIM, 152

Desvallées, André, e François Mairesse. 2010. Key Concepts of Museology. [s.1.]: ICOFOM e Armand Colin.

Dumas, Bruno, Bram Moerman, Sandra Trullemans, e Beat Signer. 2014. “ArtVis : Combining Advanced Visualisation and Tangible Interaction for the Exploration, Analysis and Browsing of Digital Artwork Collections." Proceedings of the 2014 International Working Conference on Advanced Visual Interfaces, Como, Italy, 65-72. http://dl.acm.org/citation.cfm?id=2598159

Fitzmaurice, George, Hiroshi Ishii, e William Buxton. 1995. "Bricks: Laying the Foundations for Graspable User Interfaces." CHI '95 Proceedings of the SIGCHI Conference on Human Fatores in Computing Systems. http://tmg-trackr.media.mit.edu/publishedmedia/Papers/332-Bricks\% 20Laying\%20the\%20Foundations/Published/PDF

Geser, Guntram, e Franco Niccolucci. 2012. "Virtual Museums, Digital Reference Collections and e-Science Environments." Uncommon Culture 3(5/6): 12-37.

Goodman, Elizabeth, Erik Stolterman, e Ron Wakkary. 2011. "Understanding Interaction Design Practices." Proceedings of the SIGCHI Conference on Human Factors in Computing Systems, 1061-1070. http://dl.acm.org/citation.cfm?id=1979100

Hara, Takenori, e Masafumi Oda. 2012. "Mixed Reality Mirror Display.” In SIGGRAPH Asia 2012 Emerging Technologies (SA '12), 1-3. New York: Association for Computing Machinery. 
Hernández, Francisca. 2009. "La Importancia de la Colección y Exposición dentro del Museo." ICOFOM Study Series (38): 223-235.

Hsieh, Chun-Ko, I-Ling Liu, Neng-Hao Yu, Yueh-Hsuan Chiang, Hsiang-Tao Wu, Yng-Jui Chen, e Yi-Ping Hung. 2010. "Yongzheng Emperor's Interactive Tabletop: Seamless Multimedia System in a Museum Context". Proceedings of the International Conference on Multimedia, 1453-1456. http:// dl.acm.org/citation.cfm?id=1874242

ICOM. 2007 (act.) “Definição de Museu." Conselho Internacional de Museus (ICOM). http://icomportugal.org/documentos_def,129,161,lista.aspx

Ishii, Hiroshi, e Brygg Ullmer. 1997. "Tangible Bits: Towards Seamless Interfaces Between People, Bits and Atoms." CHI '97 Proceedings of the ACM SIGCHI Conference on Human Factors in Computing Systems, 234-241. http://dl.acm.org/citation.cfm?id=258715

Israel, Karina. 2011. "Informação e Tecnologia nos Museus Interativos do Contemporâneo." Trabalho de conclusão de pós-graduação em Cultura, Mídia e Informação, Universidade de São Paulo.

Kidd, Jenny, Irida Ntalla, e Williams Lyons. 2011. "Multitouch Interfaces in Museum Spaces: Reporting Preliminary Findings on the Nature of Interaction." Proceedings of the International Conference Re-Thinking Technology in Museums 2011: Emerging Experiences. http://www.idc.ul.ie/ techmuseums11/paper/paper1.pdf

Louvre-DNP Museum Lab. 2012. "El Niño Azul, Goya and Spanish Painting in the Louvre.” [Press release], Tokyo. http://www.louvre.fr/en/ninth-louvre-dnp-museum-lab-presentation-iel-ninoazuli-goya-and-spanish-painting-louvre

Louvre-DNP Museum Lab. 2013. “A Masterpiece of Ancient Greece: A World of Men, Gods, and Heroes.” [Press release], Tokyo. http://www.museumlab.eu/press/pdf/LouvreDNPMuseumLab_10_PressRelease_EN.pdf

Morgan, Jennie. 2012. “The Multisensory Museum.” Glasnik Etnografskog Instituta 60 (1): 65-77.

Neves, Josélia. 2013. “Guias Eletrônicos em Contexto Museológico: Uma Reflexão Crítica.” Ensino em Re-Vista 20 (1): 163-178.

Norman, Donald. 2002. The Design of Everyday Things. New York: Basic Books, Inc.

Pereira, Pedro. 2013. “Os Dispositivos Móveis no Apoio a Visitas a Museus: Um Estudo da Participação Através dos Dispositivos Móveis no Apoio à Informação e Comunicação em Visitas a Museus." Tese de doutoramento em Informação e Comunicação em Plataformas Digitais, Universidade de Aveiro e Universidade do Porto.

Poulson, David, Martin Ashby, e Simon Richardson. 1996. Userfit: A Practical Handbook on Usercentred Design for Assistive Technology. Brussels: ECSC-EC-EAEC.

Preece, Jenny, Yvonne Rogers, e Helen Sharp. 2002. Interaction Design: Beyond Human-computer Interaction. New York: John Wiley \& Sons, Inc.

Rowe, Anthony. 2013. "Designing for Engagement in Mixed Reality Experiences that Combine Projection Mapping and Camera-based Interaction.” Digital Creativity, 25 (2): 155-168.

Shaer, Orit, e Eva Hornecker. 2009. "Tangible User Interfaces: Past, Present, and Future Directions." Foundations and Trends in Human-Computer Interaction 3 (1/2): 1-137.

Spinuzzi, Clay. 2002. "A Scandinavian Challenge, a US Response: Methodological Assumptions in Scandinavian and US Prototyping approaches." Proceedings of the 20th Annual International 
Conference on Computer Documentation (SIGDOC '02), 208-215. New York: Association for Computing Machinery.

Suano, Marlene. 1986. O Que é Museu. São Paulo: Brasiliense.

Vairinhos, Mário. 2014. “Artefactos Tangíveis e Adaptáveis no Ambiente Doméstico.” Tese de Doutramento em Informação e Comunicação em Plataformas Digitais, Universidade de Aveiro e Universidade do Porto.

Vaz, Roberto. 2014. "Interfaces Tangíveis no Contexto da Experiência da Visita a um Museu: 0 Caso do MM Gerdau - Museu das Minas e do Metal.” Dissertação de mestrado em Comunicação Multimédia, Universidade de Aveiro.

Veiga, Ana. 2013. Gestão de Projetos de Museus e Exposições. Belo Horizonte: C/Arte, FAPEMIG.

\section{RESUMOS}

As novas tecnologias em museus têm vindo a ser incluídas de forma gradual, possibilitando a exploração de novos meios de interação e comunicação com as exposições. O presente artigo aborda a conceção e avaliação do protótipo de um expositor interativo baseado em interfaces tangíveis para a exploração de quatro amostras geológicas pertencentes ao acervo do MM Gerdau - Museu das Minas e do Metal de Belo Horizonte, em Minas Gerais (Brasil). Para o seu desenvolvimento, foi seguida uma metodologia de design participativo, em colaboração com profissionais de geociências, educação, comunicação, design, entre outras áreas de conhecimento. Com o intuito de proporcionar uma utilização agradável do sistema por parte dos visitantes do Museu, foram adotados alguns princípios do design de interação e, para a avaliação, contou-se com a participação de 23 visitantes, três dos quais apresentavam deficiência a nível visual. Com base nos resultados, confirmou-se que este tipo de tecnologia tangível tem espaço de exploração dentro deste Museu.

New technologies are being gradually introduced into museums, allowing the exploration of new ways of interaction and communication with exhibitions. This article focuses on the design and evaluation of a displayer prototype, based on tangible user interfaces, created to explore four geological samples from the collection of MM Gerdau - Museu das Minas e do Metal, in Belo Horizonte, Minas Gerais (Brazil). For the development of this project, a methodology of participatory design was adopted, relying on the collaboration between various professionals from the geosciences, education, communication, design and other areas of expertise. In order to provide an enjoyable user experience to museum visitors, some principles of interaction design were followed. The evaluation phase engaged 23 visitors, 3 of whom were blind. From the test results obtained, it was possible to confirm the viability of this type of tangible media technology in this Museum.

\section{ÍNDICE}

Palavras-chave: MM Gerdau - Museu das Minas e do Metal, novas tecnologias da informação e comunicação, interação humano-computador, design de interacção, colecção geológica

Keywords: information and communications technology, human-computer interaction, interaction design, geological collection 


\section{AUTORES}

\section{ROBERTO VAZ}

Mestre em Comunicação Multimédia pela Universidade de Aveiro (2014), licenciado em Ciências da Engenharia Eletrónica e Telecomunicações pela mesma instituição (2012), frequenta atualmente o programa doutoral UT Austin | Portugal em Media Digitais na Universidade do Porto. Desenvolve investigação nas áreas de interação humano-computador, design de interação, tecnologia em museus e acessibilidade. Participou num projeto internacional de I\&D em associação com a unidade de investigação GRAFT - Grupo de Pesquisa em Gestão de Projetos, Arquitetura Efémera e Tecnologia em Museus, da Universidade Federal de Minas Gerais, Brasil. Desenvolveu um projeto museográfico para o MM Gerdau - Museu das Minas e do Metal, Brasil. Departamento de Engenharia Informática, Faculdade de Engenharia da Universidade do Porto, Rua Dr. Roberto Frias, s/n, 4200-465 Porto, Portugal, roberto.vaz@fe.up.pt

\section{RUI RAPOSO}

Diretor do Departamento de Comunicação e Arte da Universidade de Aveiro, Doutorado em Ciência e Tecnologias da Comunicação pela Universidade de Aveiro no ano de 2007 e licenciado em Novas Tecnologias da Comunicação pela mesma instituição em 1997. Desenvolve investigação sobre a comunicação mediada por tecnologia em contextos ligados à museologia e ao turismo (mTourism), realidade virtual e realidade aumentada no CETAC.MEDIA - Centro de Estudos das Tecnologias e Ciências da Comunicação, desde o ano de 2007.

Departamento de Comunicação e Arte da Universidade de Aveiro, Campus Universitário de Santiago, Universidade de Aveiro, 3810-193 Aveiro, Portugal, raposo@ua.pt

\section{MÁRIO VAIRINHOS}

Docente no Departamento de Comunicação e Arte da Universidade de Aveiro desde 2001, é investigador na área do Design de Interação e da Computação Humano-Computador, com interesse particular nos Media tangíveis e em Realidade Mista. Paralelamente, desenvolve trabalho de arte digital e projetos de museografia em design de interação. Foi cofundador e editor da editora de Arte Contemporânea Mimesis. Licenciado em 1996 em Economia pela Universidade de Coimbra, obteve em 2001 o grau de mestre em Artes Digitais na Universidade Católica Portuguesa. É doutorado em Ciências e Tecnologias da Comunicação pela Universidade de Aveiro e Universidade do Porto.

Departamento de Comunicação e Arte da Universidade de Aveiro, Campus Universitário de Santiago, Universidade de Aveiro, 3810-193 Aveiro, Portugal, mariov@ua.pt 